\title{
Improved BIRCH Clustering Algorithm and Human Resource Management Efficiency: An Organizational Learning Perspective
}

\author{
Yingjun Han \\ North China University of Science and Technology, Tangshan 063009, Hebei, \\ China \\ *smartwalll@163.com
}

\begin{abstract}
With the popularity of large data network, data mining technology can be used in human resource management and provide strong decision support. In this paper, the author put forward the application of BIRCH clustering algorithm in HRM database, and analyze the associated reasoning methods. Based on the multiple regression analysis, the result shows that strategic human resource management effectiveness has significant positive correlation with organizational innovation $(p<0.01)$. At the same time, the model M6 show that the nature of the enterprise has a significant negative impact on organizational learning, and the industry has positive impact on organizational learning. The conclusion shows that organizational learning plays a complete intermediary role between strategic human resource management and management innovation.
\end{abstract}

Keywords: BIRCH clustering algorithm, data mining, strategic HRM, organizational learning

\section{Introduction}

Under the background of economic globalization, innovation has become the key to maintain the competitive advantage of enterprises. Employees as the main body of enterprise innovation have the knowledge, skills and quality will affect the enterprise's innovation performance, enterprise innovation is inseparable from the human resource management [1]. Among them, the strategic human resource management practices are enterprises to accelerate the effective way of the knowledge innovation. Human resource management practice system is the main tool for enterprises to build the internal resources and capabilities based on the employees. Strategic management includes strategic planning and implementation, but the existing research focuses on the planning level, there are few studies of strategic decision making [2-3]. Strategic research on Chinese enterprises show that with raising the quality strategy, strategy implementation effectiveness and strategic gap will gradually increase; and clear strategy and strategy implementation effectiveness between contrasts increased, showing China's corporate strategy execution should be strengthened[4]. In this context, human resources management to macro organizational resource and capability obtained increasing attention. In addition, enterprise's human resource management policies and practices are also one of the most important factors that affect the organizational learning of enterprises. From the perspective of organizational learning, this paper discusses the impact mechanism of strategic human resource management effectiveness on organizational innovation.

With the development of enterprise strategy, human resources management is not only to achieve the traditional functions, but also through the best practices and other means to help enterprises achieve the goal [5]. In addition, human resources management is more actively promote the development of enterprise business strategy. Organizational learning is organizational knowledge acquisition, the process of information dissemination, information interpretation and organizational memory, realize their vision or adapt to 
environmental changes, in the individual, team and organizational level, and even the organization between, continue to produce and obtain new knowledge and behavior, and the rising cycle of interpretation, integration and institutionalization of social interaction. First of all, to explore new knowledge "feed-forward" in the process, individual level affect learning team, group and organizational level learning; secondly, in the use of existing knowledge "feedback" process, embedded in the system, strategy, structure and organizational level learning reaction than, team and individual level learning[6]. Structure and innovative research more influential, pointed out that organizations have two core of technology and management, which technology innovation is innovation of technology, products or services, and basic work activities are directly related to, management innovation is organize relevant flow process, policy and organization structure innovation in. In addition, there are two categories of product innovation and process innovation [7]. Product innovation on new products and services to meet the market demand, improve organizational performance; innovation process in the organization of production or service operation system introduced new factors, is full of opportunism, customer oriented, and nonlinear interaction.

Clustering analysis has been widely used in pattern recognition, image processing and so on. It is an important research field of data mining. The so-called cluster analysis is in accordance with properties of the thing in itself, the things are clustered; make things different clusters of similarity as far as possible small things in the same cluster similarity as large as possible [8]. Existing clustering algorithm is divided into four categories: the k-means algorithm as the representative of the partitioning clustering method, birch, representing the hierarchical clustering method to DBSCAN algorithm to represent the density clustering method and sting as the representative of the grid clustering method. The birch algorithm can used to scan through effective clustering of, especially for large data sets, but the algorithm with a diameter of controlling cluster boundary, if the sub clusters of non-spherical, not to a better clustering effect; density of cluster can discover clusters of arbitrary shape by using density DBSCAN algorithm based on, but its efficiency is low and cannot be dynamic clustering. In this paper, trees more than the $\mathrm{CF}$ tree and density clustering algorithm based on, modify the birch algorithm clustering feature (CF), as the core of the information, and the adjacent core combined into a CF tree, formed a sub cluster, makes the new algorithm can discover clusters of arbitrary shape and time complex degree and birch algorithm for the same.

\section{Data Mining and BIRCH Algorithm}

\subsection{BIRCH Algorithm}

$\mathrm{BIRCH}$ algorithm firstly stores the data set in a compact compressed format (clustering feature tree), and then directly on the compressed data structure, and does not need to cluster the original data set. In the micro clustering stage, the BIRCH method is characterized by $\mathrm{CF}$ (Feature Clustering) to describe a cluster, forming a $\mathrm{CF}$ tree. $\mathrm{CF}$ tree cannot be more than the amount of information loss in the premise, compression hierarchical structure of the cluster.

The core of BIRCH method in the micro clustering stage is the construction of $\mathrm{CF}$ tree. Assume that the data object is a data set of $\mathrm{P} n$ dimension. $\mathrm{CF}$ tree is a 3 dimensional vector, which contains the information of the data objects. Its definition is as follows:

$$
\begin{gathered}
C F=(n, L S, S S) \\
L S=\sum_{i=1}^{n} x_{i}
\end{gathered}
$$




$$
S S=\sum_{i=1}^{n} x_{i}^{2}
$$

The use of CF (cluster feature) can be derived from a part of Statistics: cluster cluster centroid $\mathrm{X}_{0}$, radius $\mathrm{R}$ and the diameter of $\mathrm{d}$.

$$
\begin{gathered}
x_{0}=\frac{\sum_{i=1}^{n} x_{i}}{n}=\frac{L S}{n} \\
R=\sqrt{\frac{\sum_{i=1}^{n}\left(x_{i}-x_{0}\right)^{2}}{n}}=\sqrt{\frac{n S S-2 L S^{2}+n L S}{n^{2}}} \\
d=\sqrt{\frac{\sum_{i=1}^{n} \sum_{j=1}^{n}\left(x_{i}-x_{j}\right)^{2}}{n(n-1)}}=\sqrt{\frac{2 n S S-2 L S^{2}}{n(n-1)}}
\end{gathered}
$$

Among them, the radius of $\mathrm{R}$ and diameter of $\mathrm{d}$ are reflected closely around the centroid of the cluster. The radius of $\mathrm{R}$ measurement the average distance to the centroid of the members, the average distance of the objects in the cluster was measured by $\mathrm{d}$.

$$
d^{*}=\sqrt{\frac{S S_{1}}{N_{1}}+\frac{S S_{2}}{N_{2}}-\frac{2 L S_{1} L S_{2}}{N_{1} N_{2}}}
$$

Among them, $\mathrm{d}^{*}$ reflects the diameter of the combined two clusters. BIRCH algorithm reads the original large-scale data sets, maps the data set into a $\mathrm{CF}$ tree in memory. CF tree node contains the CF information of each cluster. A CF tree is a highly balanced tree has two sets of parameters. A set of parameters is the branching factor, including the most each non-leaf nodes contain B branch entries, and each leaf node contains most L entries.

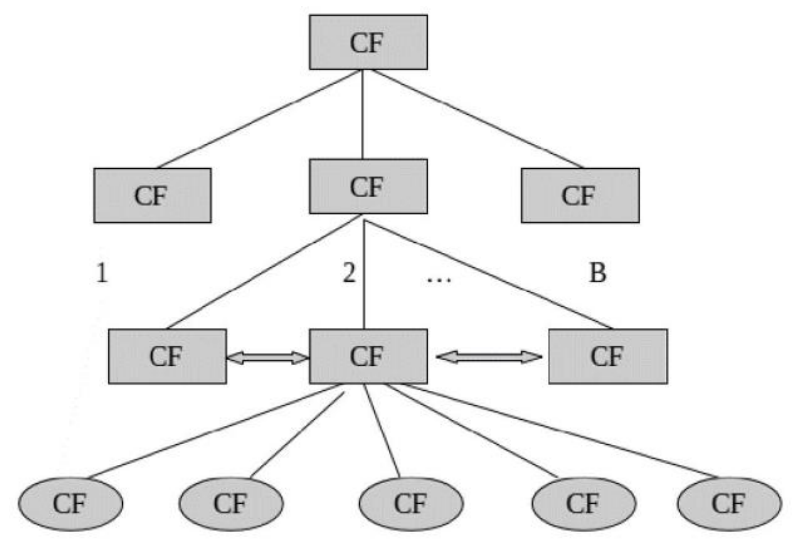

Figure 1. CF (Cluster Feature) Tree Hierarchical Structure Graph

\subsection{Associated Reasoning Methods}

In order to realize based on an evolution of knowledge networks to $\mathrm{G}_{\mathrm{T}, \mathrm{S}}, \mathrm{s}$ association inference, first of all need to find the network all may exist for relevance reasoning model, through mixed knapsack problem of finding optimal solution of different modes to choose. Known evolution of knowledge network $G_{T, S}$, the set $h$ of all instances as $H=\{h 1, h 2, \ldots$, 
$\mathrm{hn}$, which contains $\mathrm{n}$ different instances and each edge in each instance contains the edge information of time t, Le value $w(\mathrm{Le})$ as:

$$
V(l e)=\sum_{i=1}^{n} \sum_{j=1}^{3} w_{i}\left(t_{j}\right)
$$

Given a Le model contains three relationships for the E1, E2, E3, if we want to the Le model of relationship between E3 reasoning, first by traversing the graph get all meet the Le mode node types and the relationship between E1, E2 all instances of the number $\mathrm{N}$ and these examples and full foot Le modes in which the relationship between E3 examples of a number $\mathrm{n}$, Le weight $\mathrm{W}(\mathrm{Le})$ as:

$$
W(l e)=1-n / N
$$

Assume that each class contains $\mathrm{Ni}(\mathrm{I}=1,2, \ldots, \mathrm{K})$ different Le mode. In order to meet all types of relationship can be inferred, we should in each category in the selected at least a Le model. Finally the problem can be summarized as a multiple knapsack problem:

$$
\begin{aligned}
& \text { Maxmize } \sum_{i=1}^{k} \sum_{j=1}^{N_{i}} v_{i j} x_{i j} \\
& \text { s.t. } \quad \sum_{i=1}^{k} \sum_{j=1}^{N_{i}} w_{i j} x_{i j} \leq M \\
& \sum_{j \in N_{i}} x_{i j} \geq 1, x_{i j} \in\{0,1\}
\end{aligned}
$$

Since the number of entities in the network is small, the structure of the LE model is not the main time consuming part. Calculation shows the relevance reasoning process focused on the process of looking for examples of matching graph traversal and pattern,

Algorithm: Instance matching and searching algorithm

Input: evolutionary knowledge network $\mathrm{G}_{\mathrm{T}, \mathrm{S}}$, Model set $\mathrm{SLE}=\left\{\mathrm{le}_{1}, \mathrm{le}_{2}, \ldots, \mathrm{l}_{\mathrm{m}}\right\}$

Output: all modes in the collection cost, strength.

1 Initializing examples of positive cases, counterexample mapping table

2 for $\operatorname{node}_{\mathrm{i}}$ in $\mathrm{G}_{\mathrm{T}, \mathrm{S}}$

3 for relation $\mathrm{j}_{\mathrm{j}}$ in all edges connected with node $\mathrm{i}_{\mathrm{i}}$ and the other end point of relation is node $_{\mathrm{k}}$

4 If relation ${ }_{\mathrm{j}}$ and relation $\mathrm{t}_{\mathrm{l}}$ types meet l $\mathrm{e}_{\mathrm{i}}$ requirements, then

5 If node $_{\mathrm{k}}$ and node $\mathrm{e}_{\mathrm{h}}$ meet the requirements of $\mathrm{le}_{\mathrm{i}}$, then

6 the corresponding numerical of $l_{\mathrm{i}}$ in map1 plus 1

$7 \quad$ else

8 the corresponding numerical of $\mathrm{le}_{\mathrm{i}}$ in map2 plus 1

9 end if

10 end if

11 end for

12 end for

13 end for 


\section{Research Hypothesis}

\subsection{Strategic Human Resource Management and Organizational Innovation}

Although the definition of strategic human resource management there are still differences, however, the academic circles generally agree that strategic human resource management involves a series of HR related policies and practices of design, implementation, and promote the realization of business objectives through the improvement of enterprise human capital. The empirical research shows that, the effectiveness of strategic human resource management help to reduce employee turnover rate, improve the market performance of the organization. But also in the study pointed out that human resource management effectiveness only affects the market performance of the enterprise, the high performance work systems affect organizational innovation, but interaction and market performance and innovation and human resource management effectiveness of significant positive correlation. Organizational strategic human resource management to organize obtain sustainable competitive advantage for the purpose, and the organization innovation lay organizations can gain the core competitiveness, therefore, the formulation of strategic human resource management must contribute to the organizational innovation, but the strategic human resource management can effectively is key factor to determine the organizational innovation. Therefore put forward the hypothesis:

Hypothesis H1: strategic human resource management effectiveness has a significant positive effect on organizational innovation.

Hypothesis H1a: strategic human resource management effectiveness has a significant positive effect on product innovation.

Hypothesis H1b: strategic human resource management effectiveness has a significant positive effect on process innovation.

Hypothesis H1c: strategic human resource management effectiveness has a significant positive effect on management innovation.

Although relatively few studies about human resource management and organizational learning at present, but Wright (1996) stressed human resources management is an important role of organizational learning and more and more scholars began contact between human resource management and organizational learning. Organizational commitment to continuing education and training help to employees to improve their skills and learning motivation and on the internal organization of the formation the atmosphere of a kind of continuous learning and practice, so as to promote organizational learning occurs. Empirical study to test results show, strategic training, recruitment and employee participation in decision making significantly improve level of organizational learning, but salary and organizational learning not related to. Organizations for the promotion of members of the organization learning behavior and specially designed organizational learning mechanism is a combination of a series of measures, and for the promotion of organizational learning of human resource management and organizational learning mechanism of one of the organic components. Human resources management through the formulation, implementation to stimulate employee motivation, improve the learning ability of the organization learning mechanism, promote staff spontaneous learning enthusiasm, improve their behavior, form a team and group learning atmosphere, and ultimately affect the entire organization learning effect. Therefore put forward the hypothesis:

Hypothesis H2: strategic human resource management effectiveness has a significant positive effect on organizational learning. 


\subsection{Organizational Learning and Organizational Innovation}

The organization innovation is the organization to adapt to the changes of internal and external environment, including the adoption of new ideas, the introduction of new products / services, the use of new technology or new management strategies. Many studies have shown that organizational learning helps to improve organizational innovation ability, organizational innovation stems from the individual acquisition of existing knowledge, and then to share the knowledge in the organization, to promote organizational learning. From the point of view of organizational learning, there is a positive effect of knowledge acquisition and product innovation. At the same time, research shows that organizational learning is helpful to technological innovation and management innovation. The process of organizational innovation is a complex organizational learning process. Enterprise through between individuals, between individual and organizational and inter organizational information transfer, knowledge sharing, promote organizational learning to obtain new knowledge, new ideas, new skills, so as to improve the innovation ability of the organization, enhance organizational innovation performance. Therefore put forward the hypothesis:

Hypothesis H3: organizational learning has a significant positive effect on organizational innovation.

Organizational learning helps obtain heterogeneous resources in the organization, and to promote sustainable development, members of the organization as the principal part of organizational learning, learning motivation, ability will influence organizational learning, and effective human resources management can better stimulate the individual learning motivation, enhance learning ability, therefore, organizational learning and human resource management are closely related. Is a new perspective of the relationship between innovation research of human resource management and organizational innovation. The ideas put forward and implement the two stages of exploration, proposed learning helps the development of creativity, creative learning helps to push for, human resources management has an important impact on organizational learning, and organizational learning through the intermediary variables indirectly effect of organizational performance.. Therefore put forward the hypothesis:

Hypothesis H4: organizational learning plays a mediating role between strategic human resource management effectiveness and organizational innovation.

Hypothesis H4a: organizational learning plays a mediating role between strategic human resource management effectiveness and product innovation.

Hypothesis H4b: organizational learning plays a mediating role between strategic human resource management effectiveness and process innovation.

Hypothesis H4c: organizational learning plays a mediating role between strategic human resource management and management innovation.

\section{Empirical Analysis}

\subsection{Variables Measurement}

A questionnaire survey was conducted on the general manager of 112 enterprises; get the relevant data about the strategic human resource management effectiveness, organizational learning and organizational innovation. Companies in the survey, $15.1 \%$ from manufacturing, and $84.9 \%$ come from service industry; strategic human resource management effectiveness and reference to Strategic Human Resource Management Effectiveness Scale. 
Table 1. Correlation Matrix

\begin{tabular}{|c|c|c|c|c|c|c|c|c|c|c|}
\hline project & OL & KA & $\mathrm{KD}$ & $\mathrm{KI}$ & $\mathrm{OM}$ & $\mathrm{OI}$ & $\mathrm{Pi}$ & $\mathrm{Pi}$ & MI & SHR \\
\hline $\begin{array}{c}\text { Organizational } \\
\text { learning }\end{array}$ & 1 & & & & & & & & & \\
\hline $\begin{array}{l}\text { knowledge } \\
\text { acquisition }\end{array}$ & $0.838^{* *}$ & 1 & & & & & & & & \\
\hline $\begin{array}{c}\text { Knowledge } \\
\text { dissemination }\end{array}$ & $0.875^{* *}$ & $0.654 * *$ & 1 & & & & & & & \\
\hline $\begin{array}{c}\text { Knowledge } \\
\text { interpretation }\end{array}$ & $0.829 * *$ & $0.572 * *$ & $0.686^{* *}$ & 1 & & & & & & \\
\hline $\begin{array}{c}\text { Organizational } \\
\text { memory }\end{array}$ & $0.820 * *$ & $0.591 * *$ & $0.589 * *$ & $0.562 * *$ & 1 & & & & & \\
\hline $\begin{array}{c}\text { Organizational } \\
\text { innovation }\end{array}$ & $0.663 * *$ & $0.561 * *$ & $0.648 * *$ & $0.437 * *$ & $0.567 * *$ & 1 & & & & \\
\hline $\begin{array}{c}\text { Product } \\
\text { innovation }\end{array}$ & $0.565^{* *}$ & $0.521 * *$ & $0.539 * *$ & $0.366 * *$ & $0.463 * *$ & $0.866 * *$ & 1 & & & \\
\hline $\begin{array}{c}\text { Process } \\
\text { innovation }\end{array}$ & $0.539 * *$ & $0.453 * *$ & $0.522 * *$ & $0.355 * *$ & $0.470 * *$ & $0.890 * *$ & $0.672 * *$ & 1 & & \\
\hline $\begin{array}{c}\text { Management } \\
\text { innovation }\end{array}$ & $0.626 * *$ & $0.487 * *$ & $0.631 * *$ & $0.422 * *$ & $0.550 * *$ & $0.856 * *$ & $0.576 * *$ & $0.667 * *$ & 1 & \\
\hline $\begin{array}{c}\text { Strategic } \\
\text { human } \\
\text { resource }\end{array}$ & $0.553 * *$ & $0.431 * *$ & $0.485 * *$ & $0.536 * *$ & $0.416 * *$ & $0.430 * *$ & $0.382 * *$ & $0.365^{* *}$ & $0.376 * *$ & 1 \\
\hline mean value & 3.926 & 3.866 & 3.893 & 4.003 & 3.942 & 3.738 & 3.938 & 3.592 & 3.685 & 3.847 \\
\hline $\begin{array}{c}\text { standard } \\
\text { deviation }\end{array}$ & 0.685 & 0.807 & 0.866 & 0.743 & 0.841 & 0.707 & 0.848 & 0.780 & 0.808 & 0.697 \\
\hline
\end{tabular}

The table as a single dimension 6 Volume table, without test structure; such as "the human resources department of the company determine company's implementation of the strategy of human resource management problems. The internal consistency coefficient of Cronbach's $\alpha=0.868$. A total of 13 items, including knowledge acquisition, knowledge dissemination, knowledge interpretation and organizational memory, the internal consistency reliability coefficient Cronbach's $\alpha=0.928$. Confirmatory factor analysis showed that $\mathrm{X}^{2} / \mathrm{df}=88.10 / 59<3, \mathrm{GFI}=0.89, \mathrm{CFI}=0.98$, RMSEA $=0.067<0.08$, factor model of the fitting degree can accept. The organization innovation scale, product innovation, process innovation and management innovation, the internal consistency reliability coefficient Cronbach's $\alpha=0.900$. Confirmatory factor analysis showed that $\mathrm{X}^{2} / \mathrm{df}=35.14 / 23<2$, GFI $=0.91, \mathrm{CFI}=0.97, \mathrm{RMSEA}=0.069<0.08$. The average, standard deviation and correlation coefficient of the main variables are shown in table 1 . Strategic human resource management effectiveness and significantly positively related to organizational innovation and all dimensions, while significant positive correlation with organizational learning, and all dimensions; Significantly positively related to organizational learning and organization innovation.

\subsection{Multiple Regression Analysis}

From Table 2, we can see that, in order to test the impact of strategic human resource management on organizational innovation, the benchmark model M1 into the industry, the nature of the enterprise and whether listing Corporation, as a control variable. The results show that the nature of the enterprise has a significant negative impact on organizational innovation. M2 model add the strategic human resources management effectiveness, the results show that the strategic human resource management effectiveness on organizational innovation significantly positive correlation $(\mathrm{p}<0.01)$. Support hypothesis H1. To further test the effect of strategic human resource management effectiveness on different dimensions of organizational innovation, as indicated by the model M9, nature of enterprise innovative products to the significant negative correlation, strategic human resource management effectiveness of product innovation significantly positive correlation, support the hypothesis H1a; display model M12, nature of the enterprise in 
the process of innovation negatively correlated strategic human resource management effectiveness of process innovation has a significant positive correlation, support the hypothesis H1B; display model M15, strategic human resource management effectiveness of management innovation is positively related to support hypothesis H1C.

Table 2. Multiple Regression Analysis of Correlated Variables

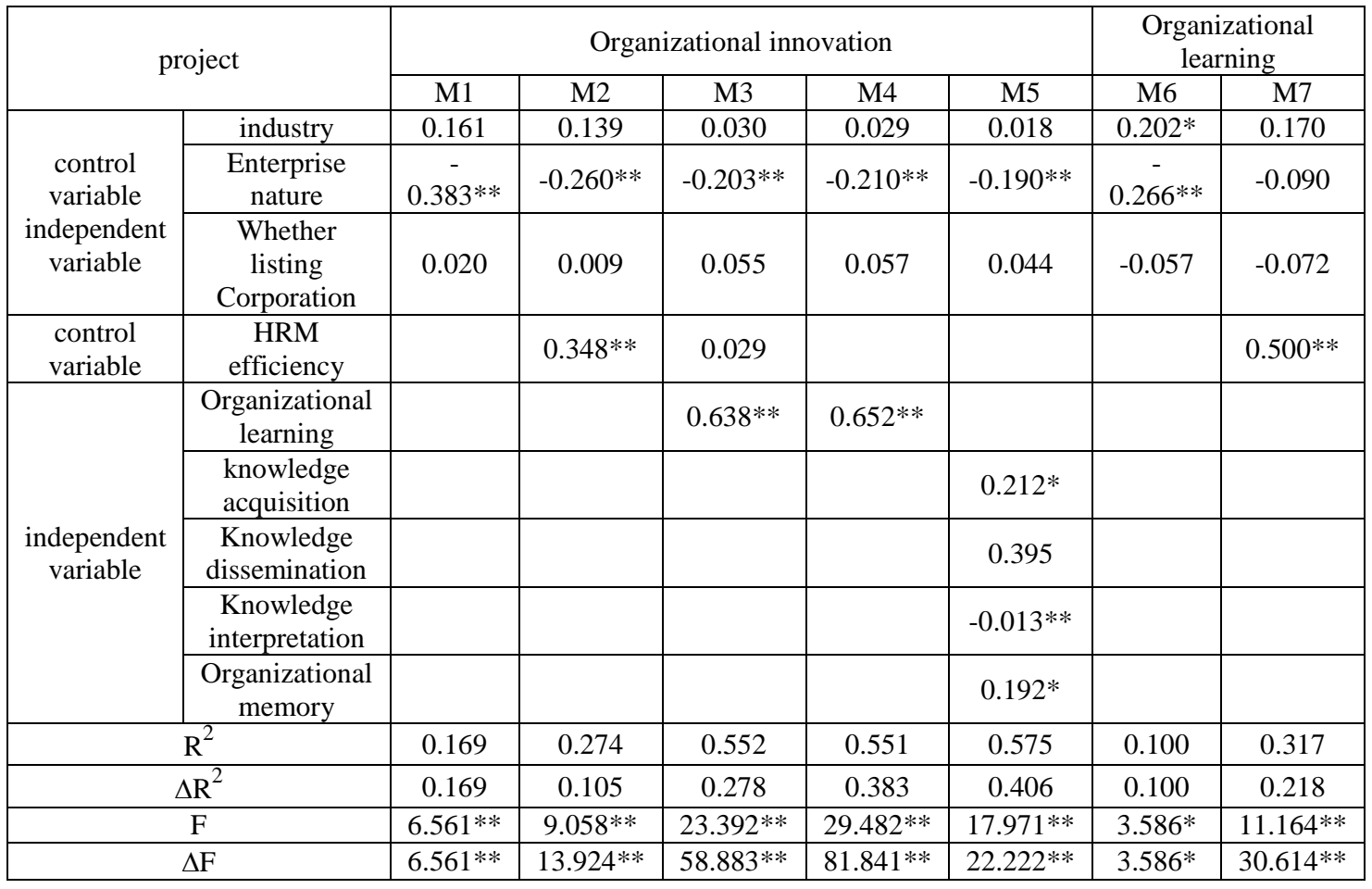

The results of the benchmark model M6 show that the nature of the enterprise has a significant negative impact on organizational learning, and the industry has a positive impact on organizational learning. After introducing the strategic human resource management effectiveness, the model M7 only has a significant positive effect on organizational learning after the strategic human resource management effectiveness. Support hypothesis H2.Model M4 shows that the nature of the enterprise is significantly negatively related to organizational innovation, organizational learning has significant positive correlation with organizational innovation. Support hypothesis H3. To further test the organization learning effect of each dimension of organizational innovation, M5 model display, enterprise nature of organizational innovation still significantly negative correlation, knowledge acquisition, memory organization on organizational innovation is related and knowledge to explain on organizational innovation is a significant negative correlation.

\subsection{The Mediating Effect of Organizational Learning}

Model M2 validation strategy human resource management effectiveness has significant positive impact on organizational innovation, model M7 validation strategy human resource management effectiveness significantly positive impact on organizational learning. Model M3 shows that after the introduction of organizational learning, strategic human resource management effectiveness on organizational innovation is no longer significant, and the regression coefficient of organizational learning to organizational innovation is 0.638 , significantly positive correlation. Therefore, organizational learning 
plays a complete intermediary role between strategic human resource management effectiveness and organizational innovation, support hypothesis $\mathrm{H} 4$.

Table 3. Multi-level Regression Analysis of Correlation Dimension

\begin{tabular}{|c|c|c|c|c|c|c|c|c|c|}
\hline \multirow{2}{*}{\multicolumn{2}{|c|}{ project }} & \multicolumn{3}{|c|}{ Product innovation } & \multicolumn{2}{|c|}{ process innovation } & \multicolumn{3}{|c|}{ Management innovation } \\
\hline & & \multirow{2}{*}{\begin{tabular}{|c|} 
M8 \\
0.141 \\
\end{tabular}} & \multirow{2}{*}{$\begin{array}{c}\text { M9 } \\
0.122 \\
\end{array}$} & \multirow{2}{*}{$\begin{array}{c}\text { M10 } \\
0.026 \\
\end{array}$} & \multirow{2}{*}{$\begin{array}{l}\text { M11 } \\
0.170 \\
\end{array}$} & \multirow{2}{*}{$\begin{array}{l}\text { M12 } \\
0.149 \\
\end{array}$} & \multirow{2}{*}{$\begin{array}{c}\text { M13 } \\
0.062 \\
\end{array}$} & \multirow{2}{*}{$\begin{array}{c}\text { M14 } \\
0.113 \\
\end{array}$} & \multirow{2}{*}{$\begin{array}{c}\text { M15 } \\
0.095\end{array}$} \\
\hline \multirow{3}{*}{$\begin{array}{c}\text { control } \\
\text { variable } \\
\text { independent } \\
\text { variable }\end{array}$} & industry & & & & & & & & \\
\hline & $\begin{array}{c}\text { Enterprise } \\
\text { nature }\end{array}$ & $\begin{array}{c}- \\
0.371 * * \\
\end{array}$ & $\begin{array}{c}- \\
0.265 * * \\
\end{array}$ & $-0.214 *$ & $0.336 * *$ & $-0.221 *$ & $-0.176 *$ & $0.296^{-} * *$ & -0.196 \\
\hline & $\begin{array}{c}\text { Whether } \\
\text { listing } \\
\text { Corporation }\end{array}$ & -0.022 & -0.031 & 0.010 & 0.042 & 0.032 & 0.069 & 0.032 & 0.023 \\
\hline $\begin{array}{c}\text { control } \\
\text { variable }\end{array}$ & $\begin{array}{c}\text { HRM } \\
\text { efficiency }\end{array}$ & & $0.300 * *$ & 0.019 & & $0.327 * *$ & 0.072 & & $0.285^{* *}$ \\
\hline $\begin{array}{l}\text { independent } \\
\text { variable }\end{array}$ & $\begin{array}{c}\text { Organizational } \\
\text { learning }\end{array}$ & & & $0.564 * *$ & & & $0.509 * *$ & & \\
\hline \multicolumn{2}{|c|}{$\mathrm{R}^{2}$} & 0.148 & 0.227 & 0.443 & 0.143 & 0.236 & 0.413 & 0.102 & 0.172 \\
\hline \multicolumn{2}{|c|}{$\Delta \mathrm{R}^{2}$} & 0.148 & 0.079 & 0.217 & 0.143 & 0.093 & 0.177 & 0.102 & 0.071 \\
\hline \multicolumn{2}{|r|}{$\mathrm{F}$} & $5.616^{* *}$ & $7.03 * *$ & $15.128 * *$ & $5.415 * *$ & $7.43 * *$ & $13.37 * *$ & $3.655^{*}$ & $5.002 * *$ \\
\hline \multicolumn{2}{|c|}{$\Delta \mathrm{F}$} & $5.616^{* *}$ & $9.751 * *$ & $36.982 * *$ & $5.415 * *$ & $11.685^{* *}$ & $28.588 * *$ & $3.655^{*}$ & $8.226 * *$ \\
\hline
\end{tabular}

From Table 3 shows, model M9 verify the strategic human resource management effectiveness of product innovation has a significant positive effect, M10 model into organizational learning, strategic human resource management and product innovation is no longer relevant, organizational learning is significantly related to product innovation. Therefore, organizational learning plays a complete intermediary role in strategic human resource management effectiveness and product innovation. Support hypothesis H4a. Model M12 verify the strategic human resource management effectiveness of process innovation has a significant positive effect, M13 model after the introduction of organizational learning, strategic human resource management effectiveness and process innovation is no longer relevant, organizational learning is significantly related to the innovation process. Therefore, organizational learning plays a complete intermediary role between strategic human resource management effectiveness and process innovation. Support hypothesis H4b. Model M15 verify the strategic human resource management effectiveness of management innovation has a significant positive effect, organizational learning is significantly related to management innovation. Therefore, organizational learning plays a complete intermediary role between strategic human resource management effectiveness and management innovation. Support hypothesis H4c.

\section{Conclusion}

In this paper, we explore the relationship between the two from the perspective of organizational learning, the introduction of organizational learning as an intermediary variable, to explore the relationship between strategic human resource management effectiveness and organizational innovation and its dimensions. Reveals the "black box" between strategic human resource management effectiveness and organizational innovation and help managers in the formulation of strategic human resource management pay more attention to on organizational learning, organizational innovation, enhance the ability of organizational innovation. Innovation is the key factor for enterprises to obtain sustainable competitive advantage and improve enterprise performance. This study shows that strategic human resource management effectiveness has significant positive correlation with organizational innovation and its dimensions. Human resource management as a series of relevant practical activities to attract, develop and maintain the organization of human resources, help to improve the enthusiasm of staff innovation, to meet the needs of improving organizational performance. Strategic human resources 
management will be a combination of human resource management and enterprise strategy, which is helpful to the successful implementation of corporate strategy. Therefore, it should be based on the overall strategy of the enterprise, the development of human resources management plan. The human resources management system involving all aspects of human resource practices and single human resource practices will lead to overestimation of the and the relationship between enterprise innovation, to the neglect of human resource practices as a whole. With foreign enterprises is introduced, the consulting industry in China's development, many local enterprises has more mature and clear strategic, but at the implementation level, there are many problems that human resources management should not be just confined to the operational level, more as the senior corporate management partners involved in strategic decision-making, but this does not mean that human resources management pay no attention to the professional skill and operation level of management, execution, it combines human resource management and the strategy of the enterprise, more strategic significance.

The results of this study indicate that organizational learning has a complete mediating effect on strategic human resource management effectiveness and organizational innovation. Must pay attention to the cultivation of innovative capabilities of individuals, through formulation helps to organizational innovation of strategic human resource management planning, human resources management into the organizational innovation strategy, promote the learning of individual knowledge and skills of employees, form of organization learning atmosphere, promoting enterprise innovation. Organization in the design of human resources management system, it is necessary to clear the importance of core employees to achieve the goal of enterprise innovation strategy, the development of the corresponding incentive mechanism to encourage employees to innovate.

\section{References}

[1] Z. Hussain and J. Wallace, "The use and impact of human resource information systems on human resource management professionals", Information \& Management, vol. 44, no. 1, (2007), pp. 74-89.

[2] A. Metin and R. Erturgut, "Importance of educated human resources in the information age and view of information society organizations on human", Procedia-Social and Behavioral Sciences, vol. 2, no. 2, (2010), pp. 1452-1456.

[3] A. Nagendra and M. Deshpande, "Human Resource Information Systems (HRIS) in HR Planning and Development in Mid to Large Sized Organizations", Procedia - Social and Behavioral Sciences, vol. 133, (2014), pp. 61-67.

[4] D. James and R. D. Johnson, "Human resource metrics and decision support: A classification frameworkOriginal”, Human Resource Management Review, vol. 23, no. 1, (2013), pp. 71-83.

[5] S. K. Brian, J. A. McClendon and T. W. Gainey, "Outsourcing HR: The Impact of organizational Characteristics", Human Resource Management, vol. 40, (2001), pp. 59-63.

[6] C. Gree and S. Gray, "Human resource management outsourcing the make or buy decision", Academy of Management Executive, vol. 13, (1999), pp. 85-96.

[7] D. L. Stone and L. Deadrick, "The influence of technology on the future of human resource management", Human Resource Management Review, vol. 25, no. 2, (2015), pp. 216-231.

[8] H. Zafar, "Human resource information systems: Information security concerns for organizations", Human Resource Management Review, vol. 23, no. 1, (2013), pp. 105-113.

\section{Author}

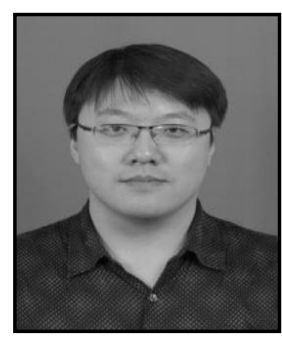

Han Yingjun, <1982.02>, <Tangshan,HeBei,P.R.China>

Current position, grades: lecturer, North China University of Science And Technology, Hebei, China

Scientific interest: His research interest fields include public administration and human resources

Publications: More than 20 papers published

Experience: He has management and teaching experience of seven years, has completed more than ten research projects 